\title{
Synthesis and characterization of porous polyurethaneurea membranes for pervaporative separation of 4-nitrophenol from aqueous solution
}

\author{
UJJAL K GHOSH, NARAYAN C PRADHAN* and BASUDAM ADHIKARI ${ }^{\dagger}$ \\ Department of Chemical Engineering, ${ }^{\dagger}$ Materials Science Centre, Indian Institute of Technology, \\ Kharagpur 721 302, India
}

MS received 22 November 2005; revised 31 January 2006

\begin{abstract}
Hydroxyterminated polybutadiene (HTPB) based porous polyurethaneurea (PUU) membranes were prepared. The porosity was developed by incorporation of lithium chloride into polymer matrix with subsequent leaching of the same in hot water. Scanning electron microscopic analysis of the prepared membrane surfaces was performed. The pervaporation performance of the synthesized membrane was studied with aqueous 4-nitrophenol solution as feed. The effects of various parameters on 4-nitrophenol separation factor and total as well as 4-nitrophenol flux were studied. Polyurethaneurea membrane was found to permeate 4-nitrophenol selectively with high separation factors for the organic component. Pore size and number of pores on the surface of the membrane were calculated from SEM image of the membranes. Effects of pore size and porosity on pervaporation flux were also investigated.
\end{abstract}

Keywords. Pervaporation; polyurethaneurea; nitrophenol; porous membrane.

\section{Introduction}

Nitrophenols are widely used as raw materials or intermediates for the manufacture of explosives, pharmaceuticals, pesticides, pigments, dyes, wood preservatives, leather, and rubber chemicals (Uberoi and Bhattacharya 1997; Karim and Gupta 2003). 4-Nitrophenol also gets produced in the atmosphere through the photochemical reaction between benzene and nitrogen monoxide and has been detected in rainwater in Japan (Karim and Gupta 2003). It is a high-priority pollutant and poses significant health and environmental risk due to its mutagenic and carcinogenic activity (Melgoza and Buitrón 2001; Bhatti et al 2002). The purification of wastewaters contaminated with this pollutant is very difficult since it is resistant to the conventional treatment techniques (Paola et al 2003). The separation of 4-nitrophenol, therefore, has become an important field of study for the sake of environmental protection. Even though many chemical methods were introduced in order to separate nitrophenols from aqueous solutions (Bielska and Szymanowski 2004; Kuscu and Sponza 2005; Purkait et al 2005), membrane separation methods like microfiltration, ultrafiltration, reverse osmosis and pervaporation are effective for separating organic pollutants from aqueous streams. Out of these processes, pervaporation appears far more effective due to its simplicity and high selectivity.

\footnotetext{
*Author for correspondence (ncp@ che.iitkgp.ernet.in)
}

Pervaporation with polymeric membranes of high permselectivity was used for effective dehydration of alcohol, recovery of aromatic compounds and separation of organic solvents. Several organophilic membranes used in pervaporation include polydimethylsiloxane (PDMS) (Wu et al 2000), poly (ether-block-amide) (Boddekar et al 1990), polyurethane (Fereira et al 2001), and silicone polyurethane copolymer (Kusakabe et al 1998). Polyurethane being a polymer with unique chain structure and morphology comprising of flexible soft segment (polyol) and rigid hard segment (diisocyanate and chain extender, viz. diol, diamine), is used for repair and replacement of the knee-joint meniscus (Spaans et al 2000), meniscal reconstruction and meniscal prostheses (Groat et al 1996).

In this communication, the use of hydroxyterminated polybutadiene (HTPB)-based porous polyurethaneurea (PUU-P) membranes is reported for the separation of 4nitrophenol from its aqueous solution by pervaporation. The performance of the membranes was monitored with variation of porosity during synthesis of the membranes. The influence of operating conditions such as the feed composition and temperature on the separation performance of the membranes was also studied.

\section{Experimental}

\subsection{Materials}

Hydroxyterminated polybutadiene (HTPB) (functionality = $2 \cdot 4$, hydroxyl value $=43.2 \mathrm{mg}$ of $\mathrm{KOH} \mathrm{g}^{-1}$ ) with a num- 
ber average molecular weight of $2580\left(M_{\mathrm{n}}\right.$, in $\left.\mathrm{g} \mathrm{mol}^{-1}\right)$ was received from VSSC (India) and was used as received. 2,4-Toluylene diisocyanate (TDI) (Fluka AG) was used without further purification. 4,4'-diaminodiphenylsulfone (DADPS) was first dehydrated under vacuum overnight and then was sublimed. The catalyst, dibutyltindilaurate (DBTDL) (Fluka AG) was used as received. Tetrahydrofuran (THF) was procured from Merck (India) and was used without further purification. Lithium chloride (LiCl) was procured from Fluka AG, Germany and 4nitrophenol was obtained from SISCO Research Laboratories, India.

\subsection{Synthesis of porous polyurethaneurea membranes}

Prepolyurethane was prepared by the reaction of HTPB and TDI in THF at $30^{\circ} \mathrm{C}$ in presence of $0.5 \mathrm{wt} \%$ DBTDL as catalyst maintaining $\mathrm{NCO}: \mathrm{OH}$ mole ratio of $2: 1$. The synthesis of prepolyurethane is chemically depicted in scheme 1 . For the synthesis of polyurethaneurea, diamine chain extender (DADPS) solution in THF of required concentration was added slowly to the reaction mixture containing prepolyurethane with constant stirring after 55 min of reaction between HTPB and TDI. The reaction was continued for a further $30 \mathrm{~min}$. The synthesis of polyurethaneurea from prepolyurethane is chemically depicted in scheme 2. To generate porosity, measured amount of $\mathrm{LiCl}$ was added to the reaction mixture. $\mathrm{LiCl}$ was used as the pore-forming agent as it is highly soluble in THF, so that it can be uniformly mixed with the polyurethaneurea solution. It is also highly soluble in water and, therefore, very easy to remove from the cast membrane by dipping into water, thereby leaving pores on the membrane. The excess solvent and entrapped bub- bles were removed from the viscous solution by evacuation. The polyurethaneurea film was cast on a clean petridish. The cast films of PUU-P having thickness of about $200 \mu \mathrm{m}$ were left overnight at room temperature for moisture curing followed by leaching in hot water at $90^{\circ} \mathrm{C}$ for $4 \mathrm{~h}$.

\subsection{Pervaporation apparatus and experimental procedure}

Pervaporation of 4-nitrophenol-water mixture was carried out in a pervaporation cell (figure 1). It is assembled from two cylindrical half-cells made of stainless steel fastened together by nuts and bolts. The membrane was supported on a sintered (perforated) stainless steel plate placed at the joint of two cells. The feed temperature was maintained by circulating hot water through the cell jacket.

The membranes used in this study were conditioned before use in the pervaporation experiments. Each membrane was kept immersed in a 4-nitrophenol-water mixture of specified composition at room temperature for $24 \mathrm{~h}$. During this period, the membrane material reached equilibrium with the liquid mixture. The membrane was then wiped dry and used in the experiments. In a typical experiment, about $180 \mathrm{ml}$ of the feed mixture of known composition was introduced into the feed chamber. For all experiments, the downstream pressure was maintained below $0.67 \mathrm{kPa}(5 \mathrm{~mm} \mathrm{Hg})$ by applying vacuum. The permeate vapour was collected in a glass condenser suspended inside a cryogenic trap kept at $-15^{\circ} \mathrm{C}$. The experiment was run for $6 \mathrm{~h}$ with no change in flux with time, confirming the steady-state operation. The effective membrane area was $28.3 \times 10^{-4} \mathrm{~m}^{2}$. The permeate material
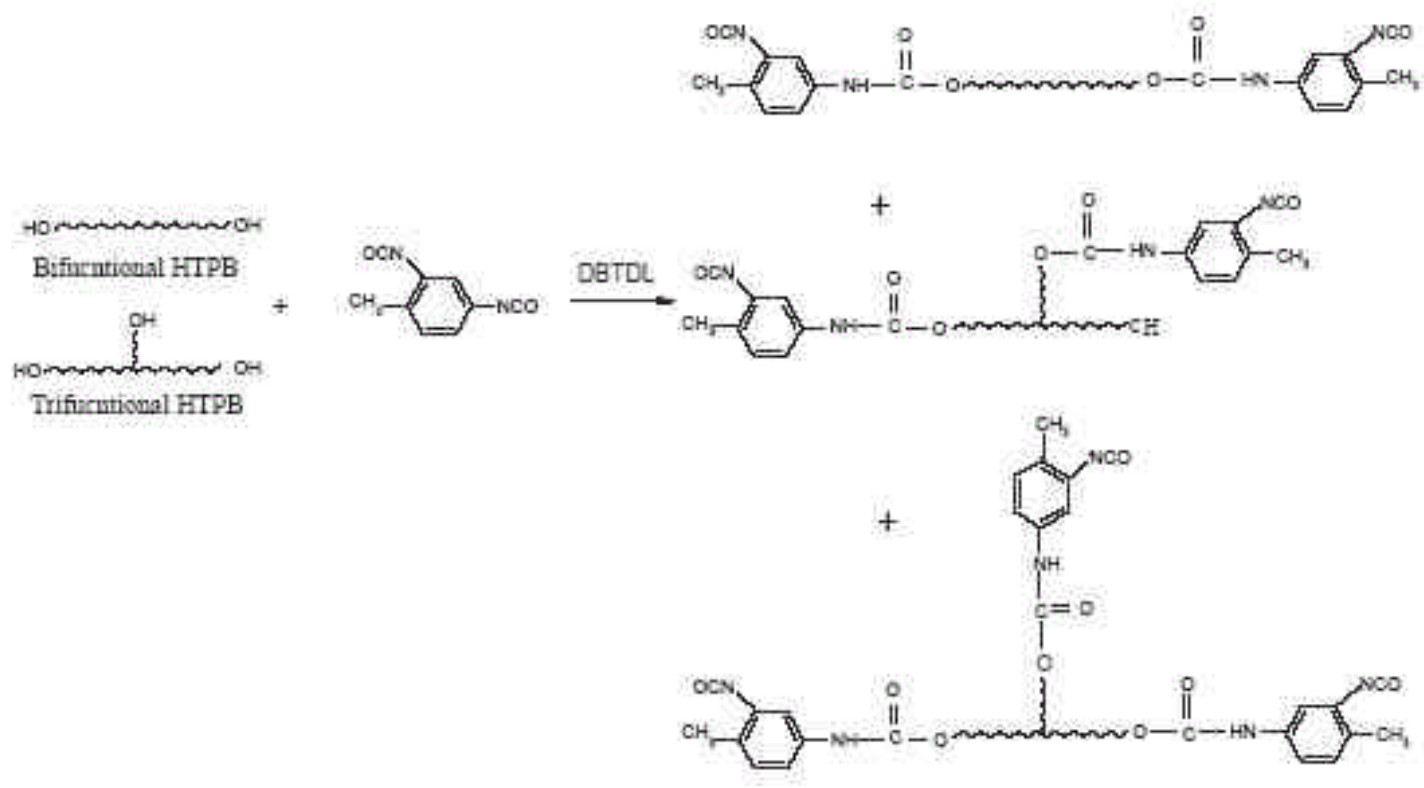

Scheme 1. Synthesis of prepolyurethane in presence of DBTDL catalyst. 


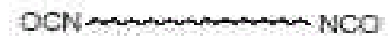
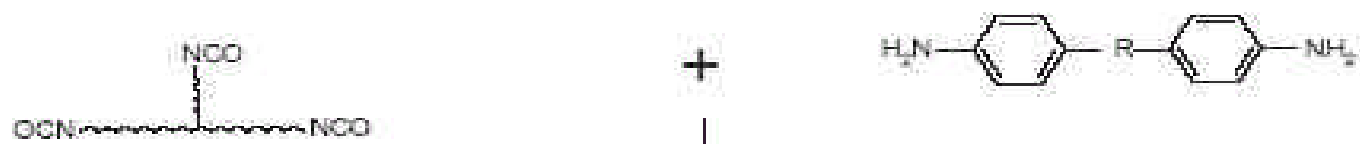

NCO terminated prepolyuretbane
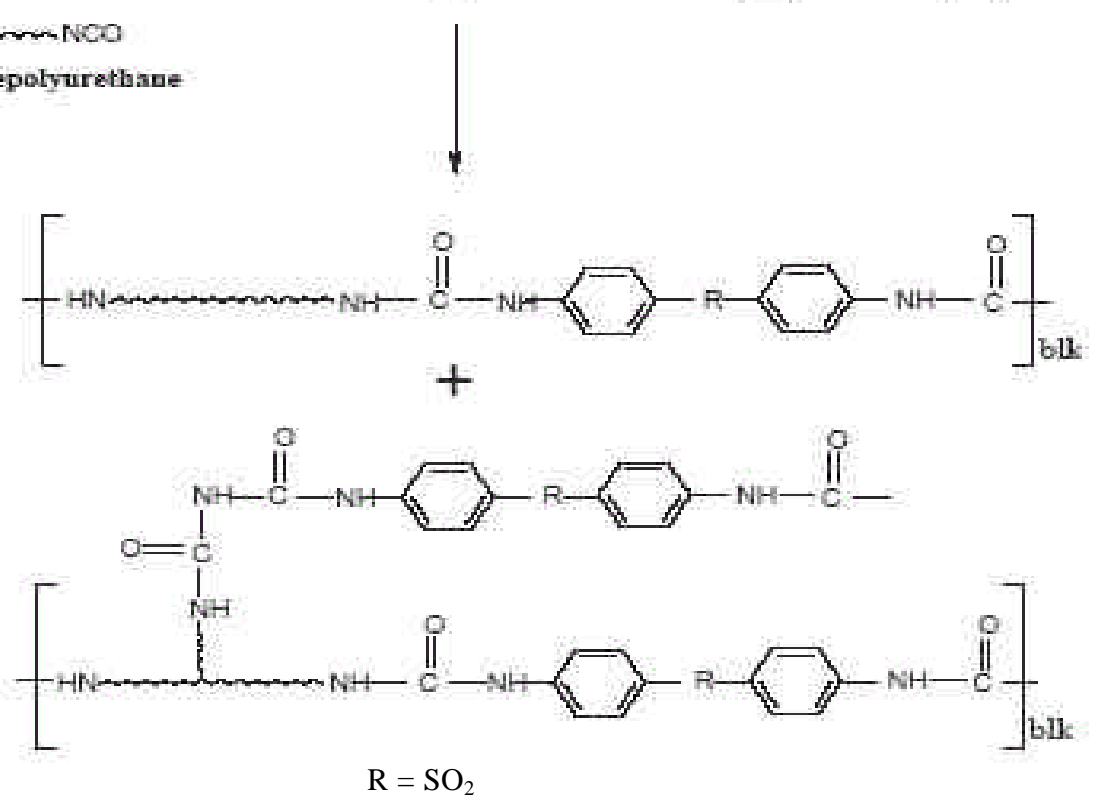

Scheme 2. Chain extension of prepolyurethane by DADPS to form polyurethaneurea.

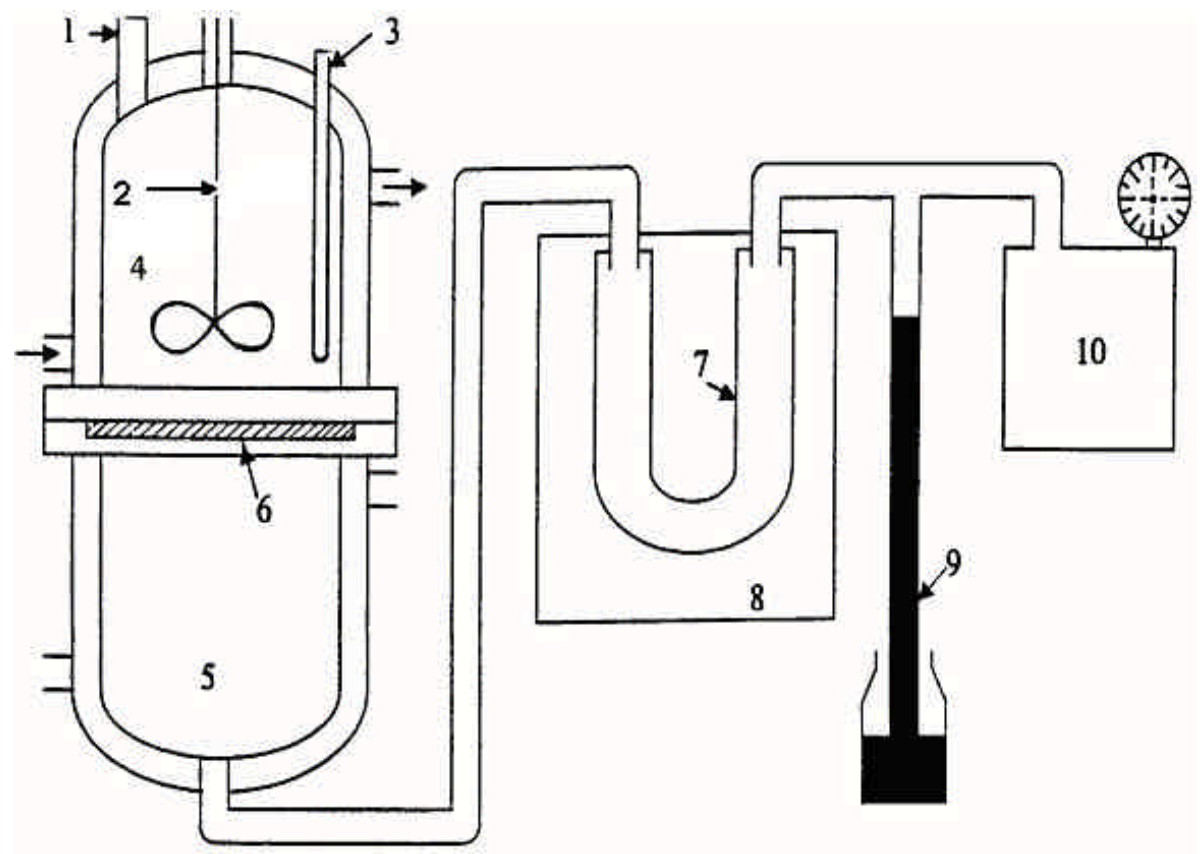

Figure 1. Sketch of the experimental set up (1. Feed inlet, 2. stirrer, 3. thermometer pocket, 4 . feed chamber, 5 . permeate chamber, 6 . sintered SS disk, 7. condenser-cumcollector, 8. cryostat, 9. manometer, 10. vacuum pump).

collected in glass condenser was weighed in a weighing balance along with the glass condenser. The weight of permeate was obtained by subtracting empty glass condenser weight from the weight of condenser with permeate.

\subsection{Analysis of permeate and estimation of membrane boundary parameter}

The permeate was analysed for 4-nitrophenol content by UV-spectroscopic analysis. The flux $(J)\left(\mathrm{g} \mathrm{m}^{-2} \mathrm{~h}^{-1}\right)$ 
of permeation was calculated from the following expression

$$
J=\frac{Q}{A t},
$$

where $Q$ is the weight of permeate (either 4-nitrophenol or water or whole permeate) obtained in a time period, $t$ and $A$ the effective membrane area. The separation factor for permeation $\left(\alpha_{\mathrm{p}}\right)$ of 4-nitrophenol is expressed as

$$
\alpha_{\mathrm{p}}=\frac{C_{i 2}}{C_{i 1}} \frac{C_{j 1}}{C_{j 2}},
$$

where $C_{i 1}$ and $C_{i 2}$ are the concentrations of 4-nitrophenol in feed and permeate, and $C_{j 1}$ and $C_{j 2}$ are the concentrations of water in feed and permeate, respectively.

\subsection{Scanning electron microscopy (SEM)}

Scanning electron microscopic analysis of the prepared porous polyurethaneurea membranes was performed using JEOL JSM-5800 Scanning Electron Microscope (JEOL, Peabody, MA). The SEM micrographs were analysed for the pores using Image Pro Plus 5.1 software.

\section{Results and discussion}

\subsection{Interpretation of SEM micrograph}

The morphology of lithium chloride-leached polyurethaneurea membranes was studied on the film surface. The SEM micrographs (figures 2(a)-(c)) of lithium chloride-modified film indicate some surface grooves/pits resulting from the loss of $\mathrm{LiCl}$ by leaching with water. The porosity and mean pore diameter data of synthesized
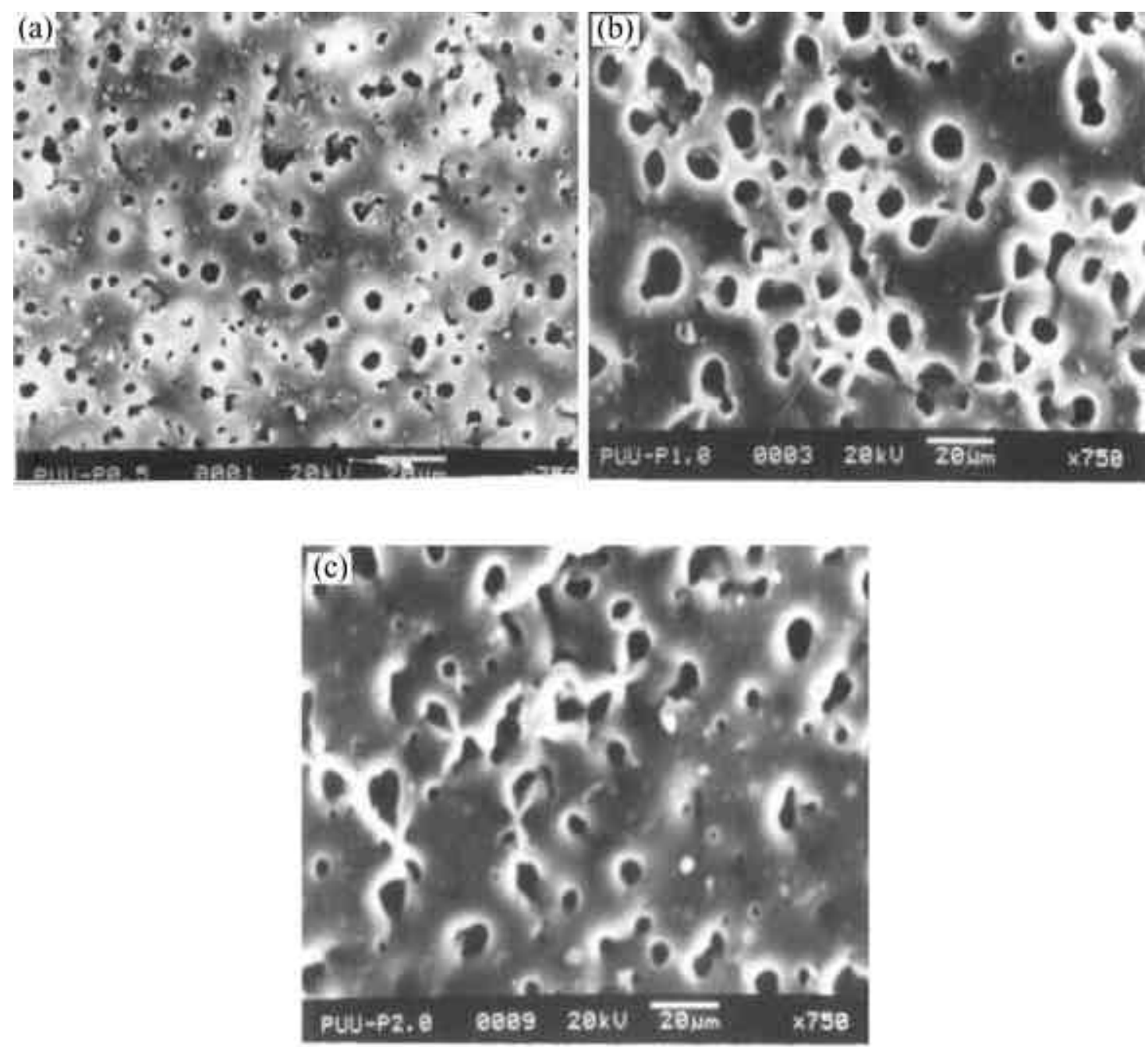

Figure 2. Scanning electron micrographs of synthesized polyurethaneurea membranes: (a) PUU-P0.5; (b) PUU-P1.0 and (c) PUU-P2.0. 
Table 1. Composition of porous polyurethaneurea membranes and their pore characteristics.

\begin{tabular}{lcccc}
\hline Membrane & $\begin{array}{c}\text { Diamine } \\
(\text { mole } \%)\end{array}$ & $\begin{array}{c}\text { Lithium chloride }^{\mathrm{b}} \\
(\text { wt \%) }\end{array}$ & Porosity & $\begin{array}{c}\text { Mean pore } \\
\text { diameter }(\mu \mathrm{m})\end{array}$ \\
\hline PUU-P0.5 & 20 & $0 \cdot 5$ & $0 \cdot 13$ & $2 \cdot 6$ \\
PUU-P1.0 & 20 & $1 \cdot 0$ & $0 \cdot 16$ & $2 \cdot 9$ \\
PUU-P2.0 & 20 & $2 \cdot 0$ & $0 \cdot 18$ & $3 \cdot 6$ \\
\hline
\end{tabular}

${ }^{\mathrm{a}}$ With respect to $M_{\mathrm{n}}$ of HTPB; ${ }^{\mathrm{b}}$ with respect to total weight of membrane material.

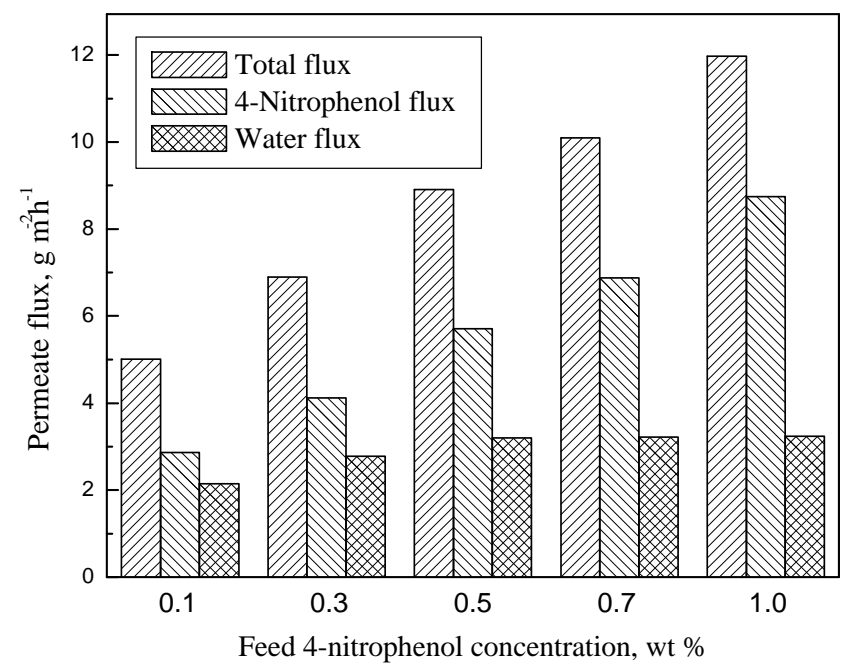

Figure 3. Variation of permeate flux with feed 4-nitrophenol concentration for PUU-P0.5 membrane (feed temperature, $\left.33^{\circ} \mathrm{C}\right)$.

lithium chloride modified polyurethaneurea membranes were given in table 1 . It can be seen from this table that the porosity and mean pore size increases as the amount of lithium chloride used during the synthesis of the membranes increases. The reason for increase in the porosity and pore diameter is that the areas of the membranes remain same when the amount of $\mathrm{LiCl}$ used is varied. As $\mathrm{LiCl}$ is the pore-forming agent, just by increasing its amount, the number of pore/unit area (and also the pore size) gets increased. Hence, PUU-P0.5 membrane had lowest porosity and shortest mean pore diameter and PUU-P2.0 membrane had highest porosity and longest mean pore diameter of the series of membranes under study.

\subsection{Effect of feed composition on permeate flux}

The effect of feed composition on permeate flux (total as well as individual) was investigated over the 4-nitrophenol concentration range $0 \cdot 1-1.0 \mathrm{wt} \%$ of 4 -nitrophenol at $33^{\circ} \mathrm{C}$ for PUU-P0.5 membrane. The individual as well as total fluxes are plotted in figure 3 as a function of feed 4-nitrophenol concentrations. It can be seen from this figure that the total flux as well as 4-nitrophenol flux increases with increasing 4-nitrophenol concentration in the feed solution. As the polyurethaneurea membrane is hydrophobic in

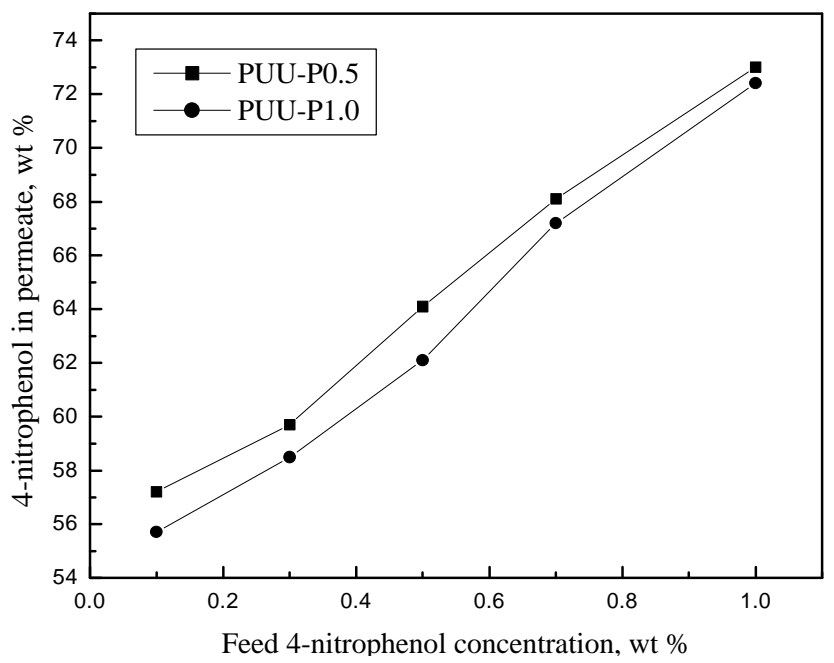

Figure 4. Variation of concentration of 4-nitrophenol in permeate with feed 4-nitrophenol concentration for PUU-P0.5 and PUU-P1.0 membranes (feed temperature, $33^{\circ} \mathrm{C}$ ).

nature, the interaction between the membrane matrix and 4-nitrophenol is higher than that of water. Increase in 4nitrophenol concentration of the feed solution increases this interaction between 4-nitrophenol and the membrane matrix. As a result, diffusion of 4-nitrophenol increases with consequent increase in 4-nitrophenol flux. Figure 3 also shows that as the feed 4-nitrophenol concentration increases, water flux first increases and then remains constant. The initial increase in water flux may be due to its higher bulk diffusion with enhanced diffusion of 4-nitrophenol. Moreover, it has been observed that the pore size increases due to interaction with nitrophenol molecule, thereby facilitating movement of water. At the same time, the driving force for water permeation (which is the difference in activity of water between the feed and the permeate sides) decreases with increase in feed 4-nitrophenol concentration with corresponding decrease in water flux. Because of these two opposing effects, the water flux remains more or less constant after a certain concentration of feed 4-nitrophenol.

\subsection{Effect of feed composition on 4-nitrophenol concentration in permeate}

The effect of feed composition on the 4-nitrophenol concentration in permeate as well as the separation factor for 
4-nitrophenol was investigated over the 4-nitrophenol concentration range $0 \cdot 1-1.0 \mathrm{wt} \%$ of 4-nitrophenol at $33^{\circ} \mathrm{C}$ for PUU-P0.5 and PUU-P1.0 membranes (figures 4 and 5). Polyurethaneurea membranes being hydrophobic in nature are selective toward 4-nitrophenol. At higher 4-nitrophenol concentration in the feed solution penetration of 4-nitrophenol molecules into the membrane is higher and, hence, the diffusivity of 4-nitrophenol is higher. Consequently, 4-nitrophenol concentration in permeate was observed to increase at higher feed 4-nitrophenol concentration (figure 4). The separation factor for 4-nitrophenol, however, decreases with its concentration in the feed solution as shown in figure 5. As defined in (2), separation factor is a ratio of the concentration ratio of 4-nitrophenol and water in permeate to that in feed. As the increase in feed concentration is more (10 times) than the increase in 4-

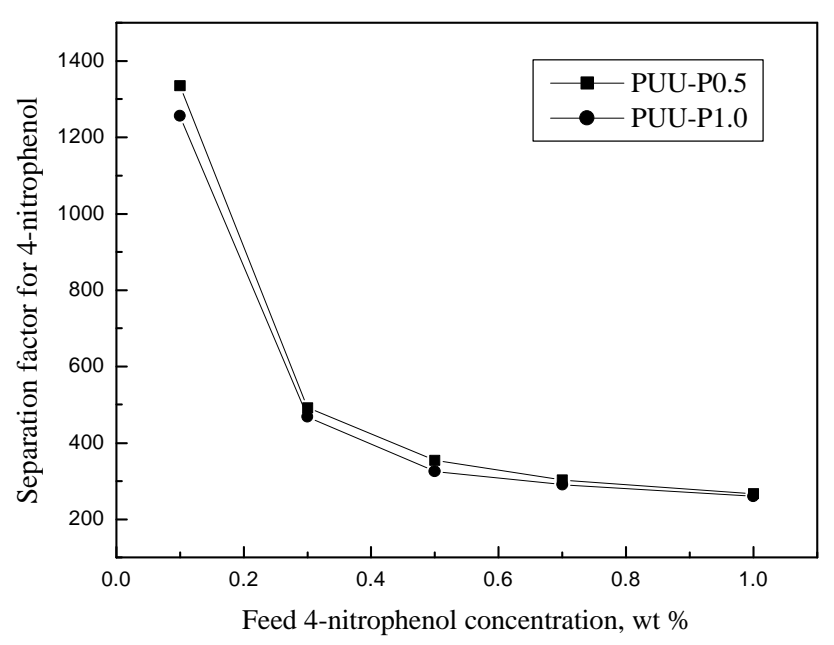

Figure 5. Variation of separation factor for 4-nitrophenol with feed 4-nitrophenol concentration for PUU-P0.5 and PUU$\mathrm{P} 1.0$ membranes (feed temperature, $33^{\circ} \mathrm{C}$ ).

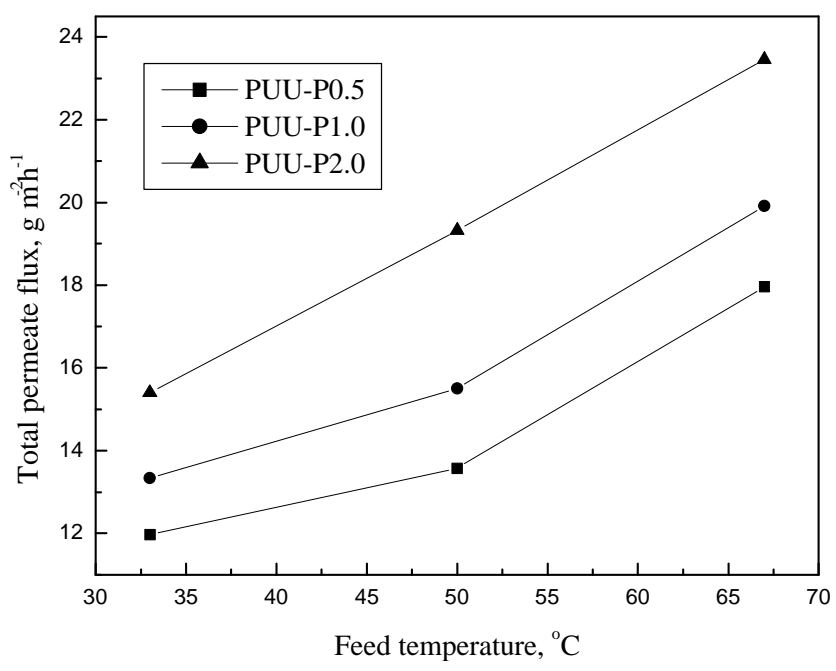

Figure 6. Variation of permeate flux (total) with feed temperature (feed 4-nitrophenol concentration, $1.0 \mathrm{wt} \%$ ). nitrophenol concentration $(\sim 1.5$ times $)$ in the permeate, the separation factor shows a decreasing trend with feed 4-nitrophenol concentration, although there is an enrichment of the permeate.

\subsection{Effect of temperature on permeate flux}

The effect of temperature on permeate flux (total as well as individual) was investigated over the temperature range $33-67^{\circ} \mathrm{C}$ for $1.0 \mathrm{wt} \%$ aqueous 4 -nitrophenol solution as feed for the porous membranes (figures 6 and 7). The total flux as well as 4-nitrophenol flux was seen to increase with increase in temperature for all the porous membranes. It is quite expected as the increase in temperature increases the diffusivities of individual compo-

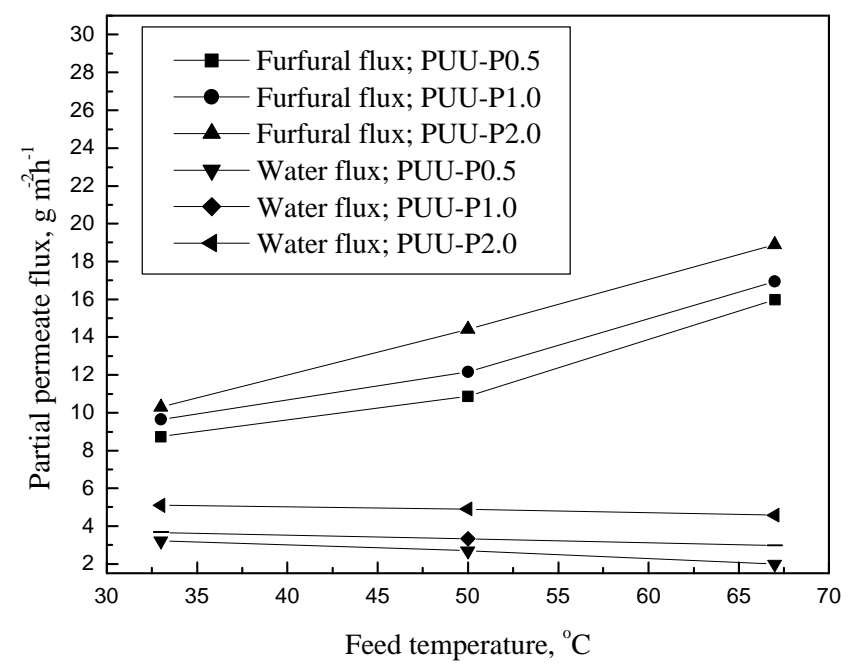

Figure 7. Variation of permeate flux (4-nitrophenol and water) with feed temperature (feed 4-nitrophenol concentration, $1.0 \mathrm{wt} \%)$.

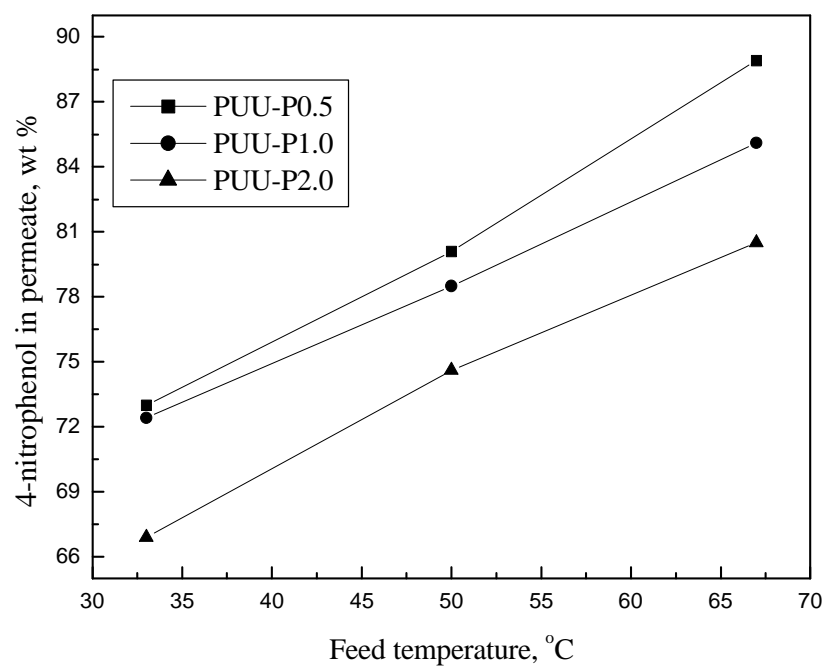

Figure 8. Variation of 4-nitrophenol concentration in permeate with feed temperature (feed 4-nitrophenol concentration, 1.0 wt \%). 
nents through the polymer membrane, thereby increasing the total and 4-nitrophenol permeate fluxes.

\subsection{Effect of temperature on 4-nitrophenol concentration in permeate}

The effect of temperature on 4-nitrophenol concentration in permeate as well as the separation factor for 4-nitrophenol was investigated over the temperature range $33-67^{\circ} \mathrm{C}$ with $1.0 \mathrm{wt} \%$ aqueous 4-nitrophenol solution as feed for the porous polyurethaneurea membranes (figures 8 and 9). The increase in 4-nitrophenol selectivity with temperature for all the membranes is evident as the diffusion of 4-nitrophenol increases more rapidly than that of water with temperature. This is expected as the hydrophobic polybutadiene segment of polyurethaneurea interacts well with 4-nitrophenol over water.

\subsection{Effect of porosity on permeate flux}

As the porosity of the membranes increased, the permeate flux (total as well as individual) increased (figures 6 and 7). This is due to the fact that as the porosity increases, it is easier for the component to travel through the membrane.

\subsection{Effect of porosity on 4-nitrophenol concentration in permeate}

As the porosity of the membranes increased, the 4-nitrophenol concentration in permeate as well as the separation

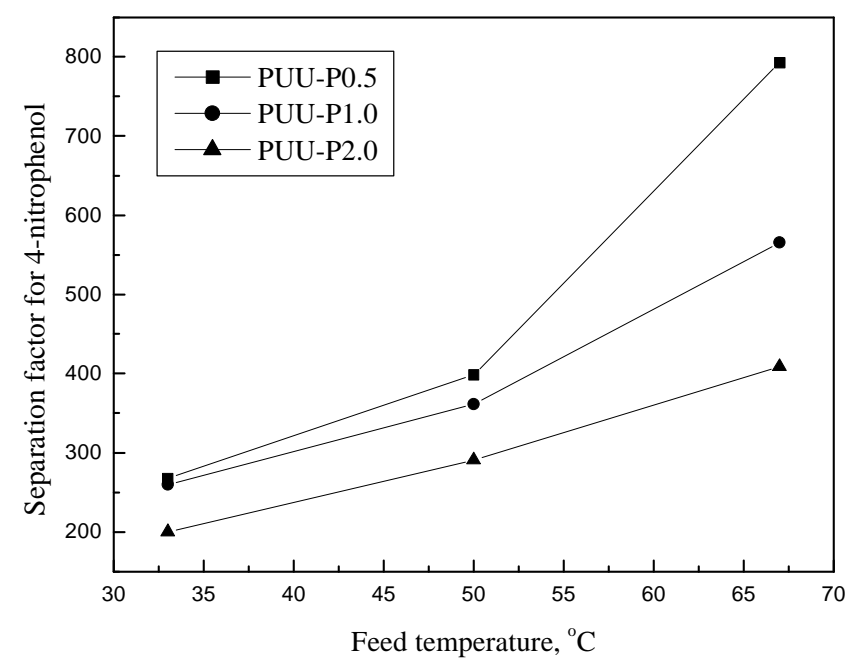

Figure 9. Variation of separation factor for 4-nitrophenol with feed temperature (feed 4-nitrophenol concentration, 1.0 wt \%). factor for 4-nitrophenol was found to decrease (figures 4, 5,8 and 9). This is due to the fact that as the porosity increases interaction between the organic component and hydrophobic membrane material decreases leading to preferential permeation of the organic component.

\section{Conclusions}

Porous polyurethaneurea membranes were prepared and tested for pervaporation characteristics with aqueous 4nitrophenol solutions. As expected, the porosity and mean pore size of the membranes increase with the increase in the amount of lithium chloride used during the synthesis. The synthesized membranes were found to be highly 4nitrophenol selective. The total flux was found to increase with temperature and concentration of 4-nitrophenol in the feed. The partial flux of 4-nitrophenol increased with an increase in 4-nitrophenol content in the feed and with an increase in feed temperature. The highest permeate flux was associated with the membrane having highest porosity and the highest separation factor for 4-nitrophenol was associated with the membrane having lowest porosity. The membranes were found to be highly suitable for the separation of 4-nitrophenol from 4-nitrophenol-water mixtures, between the experimental boundaries used in this study.

\section{References}

Bhatti Z I, Toda H and Furukawa K 2002 Water Res. 361135

Bielska M and Szymanowski J 2004 J. Membr. Sci. 243273

Boddekar K W, Bengston G and Bode E 1990 J. Membr. Sci. 53 43

Fereira L, Kaninski M, Mawson A J, Cleland D J and White S D 2001 J. Membr. Sci. 182215

Groat J H D, Vrijer R D, Pennings A J, Klompmaker J, Veth R P H and Jansen H W B 1996 Biomaterials 17163

Karim K and Gupta S K 2003 Water Res. 372953

Kusakabe K, Yoneshige S and Morooka S 1998 J. Membr. Sci. 14929

Kuscu O S and Sponza D T 2005 Enzyme Microb. Technol. 36 888

Melgoza R M and Buitr'on G 2001 Water Sci. Technol. 44151

Paola A D, Augugliaro L, Palmisano L, Pantaleo G and Savinov E 2003 J. Photochem. Photobiol. A: Chem. 155207

Purkait M K, DasGupta S and De S 2005 J. Coll. Interf. Sci. 285395

Spaans C J, Belgraver V W, Rienstra O, Groot J H D, Veth R P $\mathrm{H}$ and Pennings A J 2000 Biomaterials 212453

Uberoi V and Bhattacharya S K 1997 Water Environ. Res. 69 146

Wu P, Field R W, England R and Bridson B J $2000 \mathrm{~J}$. Membr. Sci. 190147 